\title{
Genotyping of axenic and non-axenic isolates of the genus Prochlorococcus and the OMF- 'Synechococcus' clade by size, sequence analysis or RFLP of the Internal Transcribed Spacer of the ribosomal operon
}

\author{
Wassila Laloui, ${ }^{1} \dagger$ Katarzyna A. Palinska, ${ }^{1} \neq$ Rosmarie Rippka, ${ }^{1}$ \\ Frédéric Partensky, ${ }^{2}$ Nicole Tandeau de Marsac, ${ }^{1}$ Michael Herdman ${ }^{1}$ \\ and Isabelle Iteman ${ }^{1}$
}

Author for correspondence: Isabelle Iteman. Tel: +3314568 8416. Fax: +33140613042. e-mail: iiteman@pasteur.fr

1 Unité des Cyanobactéries (CNRS URA 2172),

Département de Biochimie et Génétique Moléculaire, Institut Pasteur, 28 Rue du Dr Roux, 75724 Paris Cedex 15, France

2 Station Biologique de Roscoff (CNRS UPR 9042), BP 74, 29682 Roscoff Cedex, France
PCR amplicons of the Internal Transcribed Spacer (ITS) of the rrn operon of three axenic OMF (oceanic, marine and freshwater) strains of 'Synechococcus' (WH7803, PCC 7001 and PCC 6307, respectively) differ greatly in length from that of the axenic Proch/orococcus marinus subsp. pastoris PCC $9511^{\top}$, although these four cyanobacteria cluster relatively closely in phylogenetic trees inferred from 16S rRNA gene sequences. The ITSs of three strains (PCC 9511T, PCC 6307 and PCC 7001) were sequenced and compared with those available for strains Prochlorococcus MED4 (CCMP 1378) and MIT9313 from genome sequencing projects. In spite of large differences in length, sequence and mean DNA base composition, conserved domains important for transcriptional antitermination and folding of the rRNA transcripts were identified in all ITSs. A new group-specific primer permitted ITS amplification even with non-axenic isolates of Prochlorococcus and one OMF-' Synechococcus' strain.

Prochlorococcus isolates of the high-light-adapted clade (HL) differed from representatives of the low-light-adapted clade (LL) by the length of their ITS. Restriction fragment length polymorphism (RFLP) of the ITS amplicons revealed three subclusters among the HL strains. Size, sequence data and RFLP of the ITS amplicons will therefore be valuable markers for the identification of different Prochlorococcus genotypes and for their discrimination from other cyanobacterial relatives with which they often co-exist in oceanic ecosystems.

Keywords: Prochlorococcus marinus subsp. pastoris PCC 9511 ${ }^{\mathrm{T}}$, cyanobacteria, groupspecific ITS primers, oceanic, coastal marine and freshwater

'Synechococcus', secondary structure of the rrn operon

\section{INTRODUCTION}

Members of the genus Prochlorococcus were first

†Present address: Unité de Recherche en Génomique Végétale (INRA/CNRS), Genoscope, Centre National de Séquençage, 2, Rue Gaston Crémieux, 91057 Evry Cedex, France.

¥Present address: Carl von Ossietzky University, Geomicrobiology, PO Box 2503, 26111 Oldenburg, Germany.

Abbreviations: DV, divinyl; $\mathrm{HL}$, high-light-adapted clade; LL, low-lightadapted clade; ITS, Internal Transcribed Spacer; OMF, oceanic, marine and freshwater; RFLP, restriction fragment length polymorphism.

The GenBank accession numbers for the ITS amplicon sequences reported in this paper are AF387607 (PCC 9511'), AF387610 (PCC 6307), AF387608 (PCC 7001) and AF387609 (PCC 7941). discovered in 1988 with the aid of flow cytometry and this taxon was formally described by Chisholm et al. (1992) on the basis of the non-axenic type strain Prochlorococcus marinus CCMP $1375^{\mathrm{T}}$, isolated from the Sargasso Sea and also known as strain SS120. With cell diameters between 0.5 and $0 \cdot 8 \mu \mathrm{m}$, and an abundance of up to $5 \times 10^{5}$ cells $\mathrm{ml}^{-1}$, these oxygen-evolving photosynthetic prokaryotes occur throughout the euphotic zone, from surface layers to depths of 150-200 m, and play an important role for global primary production in tropical and temperate oceans (for a review, see Partensky et al., 1999). Although members of the cyanobacterial phylogenetic lineage (Palenik \& Haselkorn, 1992; Urbach et al., 1992; Turner, 1997), these 
oxyphototrophs differ from more typical cyanobacteria by lacking phycobilisomes and synthesizing divinyl (DV) derivatives of chlorophylls $a$ and $b$ (Partensky et al., 1999). Trace amounts of a novel type of phycoerythrin, or the genes encoding this phycobiliprotein, have been identified in some members (Hess et al., 1996, 1999; Penno et al., 2000).

Based on their preferential habitats, surface waters or deep layers receiving high or low irradiance, respectively, DV-chlorophyll $b / a$ ratios and phylogenetic position deduced from $16 \mathrm{~S}$ rRNA gene analyses, three subgroups have been recognized among isolates and environmental samples of Prochlorococcus (Morel et al., 1993; Partensky et al., 1993; Moore et al., 1995, 1998; Palenik, 1994; Urbach et al., 1998; West \& Scanlan, 1999; West et al., 2001; see also Partensky et al., 1999). Two of these (HLI and HLII) are group members of the 'high-light-adapted clades' (HL) that proliferate in surface layers of the oceans and have a very low DV-chlorophyll $b / a$ ratio. The third, loosely defined as the 'low-light-adapted clade' (LL), is composed of genetically more diverse ecotypes that exhibit higher DV-chlorophyll $b / a$ ratios and occur preferentially at depths of more than $100 \mathrm{~m}$. However, the vertical positioning is influenced by the degree of stratification of the water columns, more extensive mixing leading to the co-existence of both HL and LL ecotypes at the same depth (Moore et al., 1998; Ferris \& Palenik, 1998). In addition, the relative abundance and depth distribution of members of the HLI and HLII subclades (West \& Scanlan, 1999) may differ strikingly, depending on the geographical region (West et al., 2001).

The axenic Prochlorococcus marinus subsp. pastoris strain PCC $9511^{\mathrm{T}}$ has a low mean DNA base composition ( $32 \mathrm{~mol} \% \mathrm{G}+\mathrm{C}$ ) and a small genome ( $2 \mathrm{Mbp}$ ) (Rippka et al., 2000). However, as inferred from 16S rDNA sequence analysis, the closest phylogenetic relatives of Prochlorococcus isolates or environmental clones (Urbach et al., 1998; West \& Scanlan, 1999; West et al., 2001) are some unicellular cyanobacteria of the genetically diverse 'Synechococcus' group (Waterbury \& Rippka, 1989; Turner, 1997; Honda et al., 1999; Herdman et al., 2001). These are all of relatively small diameter $(0 \cdot 8-1 \mu \mathrm{m})$, span a mean DNA base composition in the range of $55-70 \mathrm{~mol} \% \mathrm{G}+\mathrm{C}$ (Herdman et al., 1979b, 2001; Waterbury et al., 1986; Waterbury \& Rippka, 1989) and (where known) have a genome size of about $4 \mathrm{Mbp}$ (Herdman et al., 1979a), though that of the oceanic 'Synechococcus' WH8102 is only $2 \cdot 4 \mathrm{Mbp}$ as shown by the genome sequencing project. 'Synechococcus' strains that cluster most tightly with members of Prochlorococcus, and were thus assigned to the 'marine picophytoplankton clade' (Urbach et al., 1998), have all been isolated from the open ocean (Waterbury et al., 1986; Waterbury \& Rippka, 1989) where they often co-exist with Prochlorococcus populations (Chisholm et al., 1988; Li \& Wood, 1988; Olson et al., 1990; Shimada et al., 1996; Partensky et al., 1999). In contrast, 'Synechococcus' strains that are positioned at the root of the former clade (Urbach et al., 1998; West \& Scanlan, 1999; Rippka et al., 2000; West et al., 2001) are of freshwater origin (Kane et al., 1997; Postius \& Ernst, 1999), or were isolated from a coastal marine environment (Rippka et al., 2000). To distinguish the ensemble of these related 'Synechococcus' strains (or environmental clones) from other members of the 'Synechococcus' group, that in $16 \mathrm{~S}$ rDNA trees are more remote and dispersed in several distinct phylogenetic lineages (Turner, 1997; Honda et al., 1999; Herdman et al., 2001; Robertson et al., 2001), we shall here refer to them collectively as members of the oceanic, marine and freshwater (OMF)-'Synechococcus' clade.

For a variety of reasons, precise identification of cyanobacteria by classical bacteriological criteria is difficult (Rippka et al., 1979; Castenholz \& Waterbury, 1989), but a number of different PCR-based strategies for the genetic characterization of strains, or environmental samples, are now available. Identification of Prochlorococcus genotypes has been achieved by different molecular approaches (Palenik, 1994; Ferris \& Palenik, 1998; Scanlan et al., 1996; Urbach et al., 1998; West et al., 1999, 2001), including single-cell hybridization with labelled probes and detection of the fluorescent signals by light microscopy or flow cytometry (West et al., 2001; Worden et al., 2000). However, some of these methods are labour-intensive or are based on relatively conserved RNA polymerase or $16 \mathrm{~S}$ rRNA gene sequences and thus may not provide sufficient resolution to distinguish between the different Prochlorococcus genotypes with precision. Furthermore, even discrimination of some members of Prochlorococcus from representatives of the OMF-'Synechococcus' clade may be difficult (West et al., 2001). Thus, more specific tools for the distinction within and between these two groups of organisms that often share the same ecological niche (Chisholm et al., 1988; Olson et al., 1990; Campbell \& Vaulot, 1993; Partensky et al., 1999) are still desirable.

In a survey of about 320 axenic cyanobacterial strains of the Pasteur Culture Collection of Cyanobacteria (PCC; Institut Pasteur, Paris, France), it was observed that the different sizes of the Internal Transcribed Spacer (ITS) obtained by PCR amplification correlated well (I. Iteman, unpublished results) with particular strain clusters in genetically diverse 'genera' such as 'Synechococcus' or 'Synechocystis' (Waterbury \& Rippka, 1989; Rippka \& Herdman, 1992; Herdman et al., 2001). Knowing that the ITS is less conserved than the $16 \mathrm{~S}$ rRNA gene in cyanobacteria (Wilmotte, 1994; Neilan et al., 1997; Otsuka et al., 1999; Iteman et al., 2000), we have examined the value of this domain for the genotyping of eight isolates of Prochlorococcus (one axenic, seven non-axenic) by PCR amplification, sequencing and/or RFLP of the ITS regions. For comparison, four 'Synechococcus' strains of the OMF'Synechococcus' clade (three axenic, one non-axenic) were also included in this study, one of which (PCC 6307) has previously been proposed as the type strain of 
Cyanobium gracile gen. nov., sp. nov. Rippka \& CohenBazire 1983 (Komárek et al., 1999; Herdman et al., 2001). However, since the new genus Cyanobium has not yet been validated under the Bacteriological Code of Nomenclature and may in the future also be applicable to some of the other representatives of the OMF'Synechococcus' clade, this nomenclatural change has been avoided here.

\section{METHODS}

Cyanobacterial strains. The non-axenic Prochlorococcus strains NATL2, OLI 36 FJA, GP2 (RCC296), SB (RCC295), TAK 9803-2 (RCC264) and NATL1-MIT (RCC277) were obtained from the Culture Collection of the Station Biologique, Roscoff, France (RCC). If still available from the latter collection, the corresponding RCC numbers are indicated in parentheses. The non-axenic Prochlorococcus marinus CCMP $1375^{\mathrm{T}}$ (= SS120) was kindly provided by Dr Lisa Moore [Massachusetts Institute of Technology (MIT), Cambridge, MA, USA]. The axenic strains Prochlorococcus marinus subsp. pastoris PCC 9511 ${ }^{\mathrm{T}}$ (Rippka et al., 2000) and 'Synechococcus' PCC 6307 and PCC 7001 were from the PCC (Rippka \& Herdman, 1992). 'Synechococcus' WH 7803 (axenic) was received from Dr Debbie Lindell (Steinitz Marine Biology Lab, Eilat, Israel). 'Synechococcus' TAK RED (nonaxenic) was fortuitously selected from the same primary culture that gave rise to Prochlorococcus TAK 9803-2.

Cultivation of strains. All cultures, except strains PCC 6307 and PCC 7001 , were grown at $18-20^{\circ} \mathrm{C}$ in liquid medium

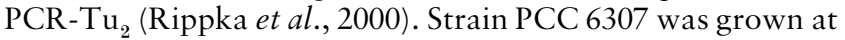
$23{ }^{\circ} \mathrm{C}$ in medium BG11 (Rippka et al., 1979). Strain PCC 7001 was cultivated in a mixture $(1: 1)$ of media BG11 and ASNIII (Rippka et al., 1979). For all strains, white light was supplied by fluorescent tubes providing during a light/dark cycle of $14 / 10 \mathrm{~h}$ a photosynthetic photon flux density (PPFD) of about $20 \mu \mathrm{m}$ photons $\mathrm{m}^{-2} \mathrm{~s}^{-1}$ (measured with a LICOR LI185B quantum/radiometer/photometer equipped with a LI190SB quantum sensor). The neon tubes were Duro-Lite (USA) for all strains, except PCC 6307 and PCC 7001, for which illumination was with Universal White neon tubes. The strain of Microcystis aeruginosa, PCC 7941, used in one control experiment, was grown in medium BG11 (Rippka et $^{2}$ al., 1979) supplemented with $\mathrm{NaNO}_{3}(2 \mathrm{mM})$ and $\mathrm{NaHCO}_{3}$ $(10 \mathrm{mM})$ under the light and temperature regimes described for strains PCC 6307 and PCC 7001. Several bacterial contaminants that also served for control PCR reactions were isolated from Prochlorococcus strains MED4 and SS120 on plates of medium PCR-Tu $\mathrm{u}_{2}$ supplemented with glucose $(0.2 \%$, $\mathrm{w} / \mathrm{v})$, Casamino acids $(0.002 \%, \mathrm{w} / \mathrm{v})$ and Luria Broth $(5 \%$, $\mathrm{v} / \mathrm{v}$ ) (Sambrook et al., 1989) and solidified with washed agar $(0 \cdot 8 \%, \mathrm{w} / \mathrm{v})$ (Rippka et al., 2000). Incubation was at $20^{\circ} \mathrm{C}$ in the dark. The purity of the axenic Prochlorococcus and 'Synechococcus' strains was routinely checked in the appropriate growth medium with the same supplements as described for the isolation of the bacterial contaminants, but solidified with Difco Bacto agar $(1 \%, w / v)$.

PCR amplification of the ITS region. Amplification of the ITS regions of Prochlorococcus and 'Synechococcus' strains was performed on cells (1-2 ml; $\mathrm{OD}_{750}$ about $0 \cdot 1$ for Prochlorococcus and 0.5-1.0 for 'Synechococcus') harvested by centrifugation $\left(15 \mathrm{~min}\right.$ at $20^{\circ} \mathrm{C}$ and $20000 \mathrm{~g}$ ), washed twice in $150 \mathrm{mM} \mathrm{NaCl}$ and resuspended in 50-200 $\mu$ l sterile $\mathrm{H}_{2} \mathrm{O}$ or TE buffer $(10 \mathrm{mM}$ Tris, $\mathrm{pH} 8 \cdot 0,0 \cdot 1 \mathrm{mM}$ EDTA). Aliquots of the cell suspensions $(1-10 \mu \mathrm{l})$ were either used directly for the PCR reactions or after lysis by five alternating cycles of freezing in liquid nitrogen and thawing at $50{ }^{\circ} \mathrm{C}$. The respective standard forward and reverse primers for amplification were $322\left(5^{\prime}\right.$ TGTACACACCGCCCGTC-3') and 340 (5'-CTCTGTGTGCCTAGGTATCC-3'), previously employed for cyanobacteria (Wilmotte et al., 1993; Iteman et al., 1999, 2000). Primer 322 initiates amplification at a region near the end of the $16 \mathrm{~S}$ rDNA on the RNA-like strand (positions 1338-1354 in Synechocystis PCC 6803; Escherichia coli numbering 13911407); primer 340 is complementary to a region on the opposite strand at the beginning of the $23 \mathrm{~S}$ rDNA (positions 26-45 in both Synechocystis PCC 6803 and E. coli). For the numbering of the E. coli rrn sequences, see Brosius et al. (1981). Alternatively, forward primer 600, designed in this study (5'-CACCTCCTAACAGGGAGACA-3') and corresponding to the last $10 \mathrm{nt}$ of the $16 \mathrm{~S}$ rDNA (E. coli numbering 1533-1542) and the first $10 \mathrm{nt}$ of the ITS on the RNA-like strand in the rrn operon of Prochlorococcus PCC 9511, was used in combination with reverse primer 340 . The higher specificity of the latter set of primers for the Prochlorococcus and 'Synechococcus' strains was tested by attempting ITS amplification on a cell suspension $\left(1 \mu \mathrm{l}, \mathrm{OD}_{750}\right.$ about 0.5$)$ of the cyanobacterium Microcystis aeruginosa PCC 7941 and lysates $(10 \mu \mathrm{l})$ of several bacterial contaminants prepared by alternating cycles of freezing in liquid nitrogen and thawing as described above. PCR amplifications with primers 322 and 340 served as positive controls.

The PCR mixture contained $10 \mu \mathrm{l}$ Taq commercial buffer $(10 \times)$ supplemented with $\mathrm{MgCl}_{2}$ to a final concentration of $2 \mathrm{mM}, 1-10 \mu \mathrm{l}$ cells or lysates as templates, $150 \mu \mathrm{M}$ each dNTP, $500 \mathrm{ng}$ each primer and $2.5 \mathrm{U}$ Taq polymerase (Promega). The total reaction volume was 50 or $100 \mu \mathrm{l}$. Incubation of the reactions was initially performed in a Perkin-Elmer Cetus Gene Amp 9700 Thermal Cycler using the following programme. After an initial cycle consisting of $5 \mathrm{~min}$ at $95^{\circ} \mathrm{C}, 1 \mathrm{~min}$ at $55^{\circ} \mathrm{C}$ and $30 \mathrm{~s}$ at $72{ }^{\circ} \mathrm{C}, 30$ cycles of amplification were started $\left(1 \mathrm{~min}\right.$ at $95^{\circ} \mathrm{C}, 1 \mathrm{~min}$ at $55^{\circ} \mathrm{C}$ and $1 \mathrm{~min}$ at $\left.72^{\circ} \mathrm{C}\right)$. The reaction was terminated by a cycle of $5 \mathrm{~min}$ at $72^{\circ} \mathrm{C}$. For later PCR reactions in a Stratagene Robocycler Gradient 40, the programme was modified: 1 cycle consisting of $5 \mathrm{~min}$ at $94^{\circ} \mathrm{C}, 1 \mathrm{~min}$ at $55^{\circ} \mathrm{C}$ and $30 \mathrm{~s}$ at $72^{\circ} \mathrm{C}$; 30 cycles of $30 \mathrm{~s}$ at $94^{\circ} \mathrm{C}, 30 \mathrm{~s}$ at $55^{\circ} \mathrm{C}$ and $30 \mathrm{~s}$ at $72{ }^{\circ} \mathrm{C}$; the final cycle was $1 \mathrm{~min}$ at $95^{\circ} \mathrm{C}, 1 \mathrm{~min}$ at $55^{\circ} \mathrm{C}$ and $5 \mathrm{~min}$ at $72^{\circ} \mathrm{C}$. Storage of the reactions in both programmes was at $4{ }^{\circ} \mathrm{C}$. A negative control without template was included in some experiments. The PCR products were analysed by electrophoresis on $1.5 \%(\mathrm{w} / \mathrm{v})$ agarose gels (Litex LSL 4000, FMC BioProducts Europe) in $1 \times$ TBE (Tris-borate-EDTA) buffer (Sambrook et al., 1989), stained with ethidium bromide $\left(0.5 \mu \mathrm{g} \mathrm{ml}^{-1}\right)$ and photographed under UV light. The length of the DNA fragments was estimated by comparison with a 100 bp DNA ladder (Amersham Pharmacia Biotech).

Cloning and sequencing of the ITS region. The PCR products of Prochlorococcus PCC 9511' ', 'Synechococcus' strains PCC 6307 and PCC 7001, and Microcystis aeruginosa PCC 7941, obtained with primers 322 and 340, were sequenced after cloning or directly on the PCR products as described by Iteman et al. (2000).

Alignment and analyses of the ITS sequences. Alignment of the ITS sequences of Prochlorococcus PCC 9511' and 'Synechococcus' PCC 6307 and PCC 7001, together with those of Prochlorococcus MED4 and MIT9313, available from the genome sequencing projects, were made manually using Genedoc v. 2.5 (http://www.psc.edu/biomed/genedoc/) and by reference to the cyanobacterial ITS alignment and second- 
Table 1. Origin and genotypes of Prochlorococcus and 'Synechococcus' strains examined

The two strains for which the genome sequences are available (Prochlorococcus MED4 and MIT9313) and whose ITS sequences were aligned to those determined in this study are also included in this table.

\begin{tabular}{|c|c|c|c|}
\hline Strain/genome sequence & Origin/depth & Genotype* & Reference $†$ \\
\hline \multicolumn{4}{|l|}{ Prochlorococcus } \\
\hline \multicolumn{4}{|l|}{ Axenic } \\
\hline Prochlorococcus PCC $9511^{\mathrm{T}}$ & Sargasso Sea, $120 \mathrm{~m} \neq$ & HLI & $1,2,3,4,5$ \\
\hline \multicolumn{4}{|l|}{ Non-axenic } \\
\hline Prochlorococcus NATL2 & North Atlantic, $30 \mathrm{~m}$ & HLI & 4,5 \\
\hline Prochlorococcus GP2 & West Pacific, $150 \mathrm{~m}$ & HLII & $4,5,6$ \\
\hline Prochlorococcus SB & Sugura Bay, Japan, $40 \mathrm{~m}$ & HLII & $4,5,7$ \\
\hline Prochlorococcus TAK 9803-2 & Takapoto atoll, Pacific, $20 \mathrm{~m}$ & HLII & 4,5 \\
\hline Prochlorococcus OLI 36 FJA & Equatorial Pacific, $100 \mathrm{~m}$ & Unknown & 8 \\
\hline Prochlorococcus NATL1-MIT & North Atlantic, $30 \mathrm{~m}$ & LL & 4,5 \\
\hline Prochlorococcus CCMP $1375^{\mathrm{T}}$ (SS120) & Sargasso Sea, $120 \mathrm{~m}$ & LL & $1,2,4,5$ \\
\hline \multicolumn{4}{|l|}{ 'Synechococcus' } \\
\hline \multicolumn{4}{|l|}{ Axenic } \\
\hline 'Synechococcus’ PCC 7001 & Intertidal mat, New York, USA & OMF-SYN & 1,9 \\
\hline 'Synechococcus' PCC 6307 & Lake water, Wisconsin, USA & OMF-SYN & $1,2,9$ \\
\hline ‘Synechococcus’ WH7803 & North Atlantic, surface & OMF-SYN & 10,11 \\
\hline \multicolumn{4}{|l|}{ Non-axenic } \\
\hline 'Synechococcus' TAK RED & Same as TAK 9803-2 & Unknown & This study \\
\hline \multicolumn{4}{|l|}{ Genome sequences } \\
\hline Prochlorococcus MED4 (CCMP 1378) & Mediterranean Sea, $5 \mathrm{~m}$ & HLI & $2,3,4,5$ \\
\hline Prochlorococcus MIT9313 & North Atlantic, $135 \mathrm{~m}$ & LL & $3,4,5,11,12$ \\
\hline
\end{tabular}

* The distinction between HLI and HLII is according to West \& Scanlan (1999) and West et al. (2001). OMF-SYN, OMF- 'Synechococcus'. †Only references appropriate for the description of the isolates or assignment to phylogenetic clusters (genotypes) are provided. 1, Chisholm et al. (1992); 2, Urbach et al. (1998); 3, Rippka et al. (2000); 4, Partensky et al. (1999); 5, West \& Scanlan (1999); 6, Shimada et al. (1996); 7, Shimada et al. (1995); 8, F. Partensky, unpublished; 9, Rippka et al. (1979); 10, Waterbury et al. (1986); 11, West et al. (2001); 12, Moore et al. (1998).

$\ddagger$ The origin of the axenic strain PCC $9511^{\mathrm{T}}$ is somewhat doubtful (see Rippka et al., 2000).

ary structure models of the rRNA transcripts proposed by Iteman et al. (2000).

Analyses of the $16 \mathrm{~S}$ rDNA-ITS overlapping regions. The sequences of the 16S rDNA-ITS overlapping regions of Prochlorococcus MED4 and MIT9313, and 'Synechococcus' WH8102, located on contigs 26, 478 and 52, respectively, were obtained by consultation of the genome sequencing projects (http://www.jgi.doe.gov/JGI_microbial/html/prochlorococcus/prochlo_pickastrain.html and http://www.jgi.doe. gov/JGI_microbial/html/synechococcus/synech_homepage.html).

The GenBank accession numbers of additional 16S rDNA, ITS or 16S rDNA-ITS sequences used to investigate the specificity of primer 600 are as follows: Synechococcus PCC 6301, X00436; Synechocystis PCC 6803, D90916; Spirulina PCC 6313, X75045; Arthrospira PCC 8005, X70769; Arthrospira PCC 7345, X75044; environmental clone ENV WH7B, AJ007374; Spirulina subsalsa FACHB351, AF329394; all these sequences contain both the $16 \mathrm{~S}$ rDNA and the ITS region. For the following strains two sequences were necessary to cover the 16S rDNA-ITS junction: Trichodesmium NIBB1067, X70767 (16S rDNA) and X72871 (ITS); Anabaena (Nostoc) PCC 7120, X59559 (16S rDNA) and AF180968 (ITS); Nodularia BCNOD 9427, AJ224447 (16S rDNA) and
AJ224448 (ITS). For strains Pseudanabaena PCC 7403 and PCC 7409, and 'Chlorogloeopsis' PCC 7518 (X687580; 16S rDNA), the $16 \mathrm{~S}$ rDNA sequence and/or corresponding ITS were kindly provided by Gerard Van der Auwera and Annick Wilmotte (see also Iteman et al., 2000).

The sequences of the $16 \mathrm{~S}$ rDNA-ITS junctions of Arthrospira OUQDS6 (AF329393), FACHB438 (AF329392) and FACHB439 (AF329391) are identical to that of Arthrospira PCC 7345 and, as for the corresponding sequence of Nostoc PCC 73102 (that shares $100 \%$ sequence identity in this domain with strain Anabaena PCC 7120), are not included in Fig. 4, but were counted in the total of 24 cyanobacterial $16 \mathrm{~S}$ rDNA-ITS junctions compared (see Discussion). The $16 \mathrm{~S}$ rDNA and ITS sequences of Nostoc PCC 73102 are both located on contig 647, available from the genome sequencing project (http://www.jgi.doe.gov/JGI_microbial/ $\mathrm{html} /$ nostoc/nostoc_homepage.html).

Restriction endonuclease digestion of the ITS amplicons. After amplification with primer pair 600 and 340, the PCR products $(10-20 \mu \mathrm{l})$ of the Prochlorococcus strains were digested with $5 \mathrm{U}$ of the following restriction enzymes: $A l u \mathrm{I}$, DdeI, EcoRI, EcoRV, HaeIII, HinfI and HindIII (Gibco-BRL, 
Life Technologies), according to the instructions of the manufacturer. The DNA fragments were separated by electrophoresis for $4-6 \mathrm{~h}$ at $60 \mathrm{~V}$ on $2.5 \%(\mathrm{w} / \mathrm{v})$ agarose gels (Metaphor, FMC, BioProducts) in $1 \times$ TBE buffer (Sambrook et al., 1989). Staining, DNA size markers and visualization of the restriction fragments were as described above.

\section{RESULTS}

\section{Strain description}

The origin and phylogenetic assignments of the axenic and non-axenic strains of Prochlorococcus and 'Synechococcus' examined in this study, or whose published ITS sequences were used for comparative analyses (Prochlorococcus strains MED4 and MIT9313), are described in Table 1. 'Synechococcus' WH7803 is a representative of the open ocean (Waterbury et al., 1986) and a close relative of 'Synechococcus' WH7805 (Urbach et al., 1998; West et al., 2001); both, like the impure strain TAK RED, have a high phycoerythrin content (Waterbury et al., 1986; R. Rippka, unpublished observation). Strains 'Synechococcus' PCC 6307 and PCC 7001, more distantly related to the former oceanic strains (Urbach et al., 1998; Rippka et al., 2000), are of freshwater origin or isolated from a coastal marine environment, respectively, and neither of them synthesize phycoerythrin (Waterbury \& Rippka, 1989; Herdman et al., 2001).

\section{Amplification of the ITS region with primers 322 and 340}

With primers 322 and 340, a single PCR amplicon of different size was observed for the axenic strains Prochlorococcus PCC $9511^{\mathrm{T}}$ and 'Synechococcus' PCC 6307, PCC 7001 and WH7803 (Fig. 1a; Table 2). After subtraction of a total of $200 \mathrm{bp}$ contributed by the end of the $16 \mathrm{~S}$ rDNA (150 bp) and the beginning of the $23 \mathrm{~S}$ rDNA $(50 \mathrm{bp})$, the sizes of the ITS regions amounted to about $550 \mathrm{bp}$ for Prochlorococcus PCC 9511 ${ }^{\mathrm{T}}$ and to about 1000, 1100 and $800 \mathrm{bp}$, respectively, for 'Synechococcus' PCC 6307, PCC 7001 and WH7803. However, amplifications with these primers performed on the non-axenic strains of Prochlorococcus and 'Synechococcus' TAK RED yielded one major and one or more minor PCR products. The more intense bands observed (a)

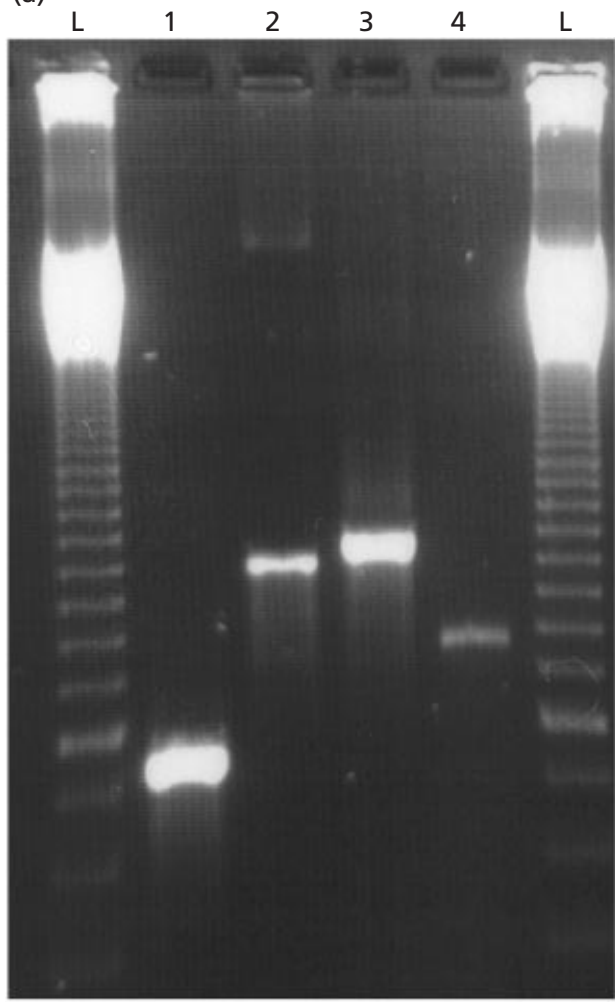

(b)

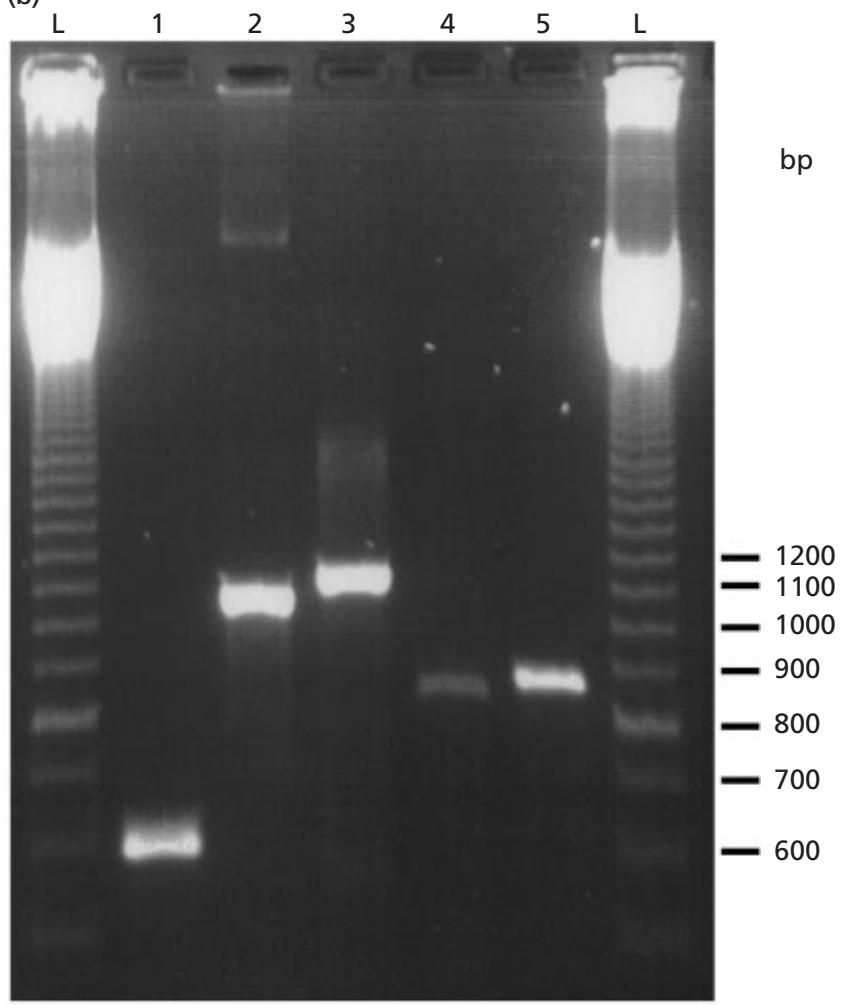

Fig. 1. Agarose gels showing the PCR products obtained by amplification of the ITS regions with two different sets of primers. (a) ITS amplicons with primer set 322 and 340 obtained with four axenic strains of Prochlorococcus and 'Synechococcus'. Lanes: 1, Prochlorococcus PCC 9511'; 2, 'Synechococcus' PCC 7001; 3, 'Synechococcus' PCC 6307; 4, 'Synechococcus' WH 7803. (b) PCR products after amplification of the ITS regions with primer set 600 and 340. Lanes: 1, Prochlorococcus PCC 9511'; 2, 'Synechococcus' PCC 7001; 3, 'Synechococcus' PCC 6307; 4, 'Synechococcus' WH7803; 5, 'Synechococcus' TAK RED (non-axenic). Lanes L, 100 bp molecular mass ladder. 
Table 2. Sizes of the PCR products obtained for Prochlorococcus and 'Synechococcus' isolates with two different sets of primers (322 and 340; 600 and 340) and groupings of Prochlorococcus strains based on size and RFLP profiles of the ITS amplicons obtained with primer set 600 and 340

\begin{tabular}{|c|c|c|c|c|c|c|c|c|}
\hline \multirow[t]{3}{*}{ Strain } & \multirow[t]{3}{*}{ Genotype* } & \multicolumn{2}{|c|}{$\begin{array}{l}\text { Size (bp) of PCR amplicon or ITS } \\
\quad \text { (in parentheses) with primers: } †\end{array}$} & \multirow{3}{*}{$\begin{array}{l}\text { ITS RFLP } \\
\text { cluster }\end{array}$} & \multicolumn{4}{|c|}{ Enzyme and length (bp) of restriction fragmentsł } \\
\hline & & & & & $A l u \mathrm{I}$ & DdeI & HinfI & HaeIII \\
\hline & & 322 and 340 & 600 and 340 & & & & & \\
\hline \multicolumn{9}{|l|}{ 'Synechococcus' } \\
\hline PCC 6307 & OMF-SYN & $1200(1010)^{\mathrm{a}}$ & $1050(1010)^{\mathrm{a}}$ & ND & ND & ND & $\mathrm{ND}$ & ND \\
\hline PCC 7001 & OMF-SYN & $1300(1065)^{\mathrm{a}}$ & $1100(1065)^{\mathrm{a}}$ & ND & ND & ND & ND & ND \\
\hline WH7803 & OMF-SYN & $1000(800)$ & $880(820)$ & ND & ND & ND & ND & ND \\
\hline TAK RED & Unknown & $1000 \$(800)$ & $890(830)$ & ND & ND & ND & $\mathrm{ND}$ & $\mathrm{ND}$ \\
\hline \multicolumn{9}{|l|}{ Prochlorococcus } \\
\hline PCC $9511^{\mathrm{T}}$ & HLI & $750(548)^{\mathrm{a}}$ & $600(548)^{\mathrm{a}}$ & \multirow{3}{*}{ I.1 } & \multirow{3}{*}{$170,140(\mathrm{~d}), 80$} & \multirow{3}{*}{$260,130,80$} & \multirow{3}{*}{$210(\mathrm{~d})$} & \multirow{3}{*}{400,140} \\
\hline NATL2 & HLI & $750 \$(550)$ & $600(540)$ & & & & & \\
\hline OLI 36 FJA & Unknown & $750 \$(550)$ & $600(540)$ & & & & & \\
\hline TAK 9803-2 & HLII & $750 \$(550)$ & $600(540)$ & I.2A & \multirow{3}{*}{$170,150,140,80$} & \multirow{3}{*}{380,80} & \multirow{3}{*}{$290,200,80$} & \multirow{3}{*}{$\begin{array}{l}400,140 \\
380,230\end{array}$} \\
\hline GP2 & HLII & $750 \$(550)$ & $600(540)$ & \multirow{2}{*}{ I.2B } & & & & \\
\hline SB & HLII & $750 \mathbb{S}(550)$ & $600(540)$ & & & & & \\
\hline SS120 & LL & $850 \sqrt{ }(650)$ & $700(640)$ & \multirow{2}{*}{ II } & \multirow{2}{*}{$240,190,150,70$} & \multirow{2}{*}{$310,130,90,70$} & \multirow{2}{*}{$380,200,130$} & \multirow{2}{*}{500,13} \\
\hline NATL1-MIT & LL & $850 \$(650)$ & $700(640)$ & & & & & \\
\hline
\end{tabular}

ND, Not determined.

* The distinction between HLI and HLII is according to West \& Scanlan (1999) and West et al. (2001). OMF-SYN, OMF-'Synechococcus'. † Since the amplicons include part of the adjacent $16 \mathrm{~S}$ rDNA and $23 \mathrm{~S}$ rDNA, the true ITS sizes (indicated in parentheses) were either determined from the ITS sequences $\left({ }^{\mathrm{a}}\right)$ or calculated by subtracting $200 \mathrm{bp}$ from the amplicons if using primers 322 and 340 and 60 bp if using primers 600 and 340 .

$\ddagger$ Fragments indicated with (d) for 'doublets' had a slightly stronger fluorescence and correspond most likely to two different restriction fragments of very similar size (see Results).

\Although minor bands were generated by the contaminants with primers 322 and 340, only the sizes of the major PCR products are given.

for five of the impure Prochlorococcus strains (Table 2) were similar in size (PCR product about $750 \mathrm{bp}=$ ITS of $550 \mathrm{bp}$ ) to the ITS amplicon of the axenic Prochlorococcus PCC $9511^{\mathrm{T}}$ (see Fig. 1a), but they were larger (PCR product about $850 \mathrm{bp}=$ ITS of $650 \mathrm{bp}$ ) for strains SS120 and NATL1-MIT (Table 2). The major PCR product of the impure strain 'Synechococcus' TAK RED amounted, as for the axenic 'Synechococcus' WH7803 (Fig. 1a; Table 2), to an ITS size of about 800 bp (Table 2).

The minor bands repeatedly observed with primer set 322 and 340 were undoubtedly the result of bacterial contamination. This was confirmed on cell lysates of five bacterial strains isolated from two different Prochlorococcus cultures and for which ITS sizes of 280, 580, 680, 700 and 900 bp could be determined (data not shown). As shown by our analyses by NCBI BLASTN 2.1.3 (http://www.ncbi.nlm.nih.gov/blast/), the region complementary to primer 322 is well conserved among many prokaryotes, but that complementary to primer 340 corresponds to a signature sequence typical of the $23 \mathrm{~S}$ rRNA gene in cyanobacteria and chloroplasts. Hence, the primer set 322 and 340 is relatively specific for cyanobacteria (Wilmotte et al., 1993; Iteman et al., 2000), However, as evidenced by the positive amplification results with the contaminants, conservation of both primer regions seems also to be typical of the marine bacteria associated with the impure Prochlorococcus and 'Synechococcus' strains examined.

\section{Amplification of the ITS region with primers 600 and 340}

Given that the standard set of primers (322 and 340) amplified the ITS of the contaminants, forward primer 322 was replaced by primer 600 , whose oligonucleotide sequence was designed on the basis of the $16 \mathrm{~S}$ rDNA and ITS sequences of the axenic Prochlorococcus PCC $9511^{\mathrm{T}}$ (see below). Amplifications with this new set of primers performed on the axenic Prochlorococcus PCC $9511^{\mathrm{T}}$ and 'Synechococcus' strains PCC 6307, PCC 7001 and WH7803 gave ITS amplicons of the expected size (compare Fig. 1a, b; see also Table 2). After subtraction of the $60 \mathrm{bp}$ contributed by the end of the $16 \mathrm{~S}$ rDNA (10 bp) and the beginning of the $23 \mathrm{~S}$ rDNA (50 bp), the length of the ITS regions amounted, respectively, to about 540, 1000, 1050 and 820 bp, which is in good agreement with the estimates based on amplifications with primers 322 and 340 (Fig. 1a). No additional bands were observed for the impure strain 'Synechococcus' TAK RED (Fig. 1b) and the non-axenic Prochlorococcus isolates (Table 2), demonstrating the higher specificity of the new set of primers. Furthermore, PCR reactions performed at the same temperature $\left(55^{\circ} \mathrm{C}\right)$ as that used for the Prochlorococcus and 'Synechococcus' strains, 


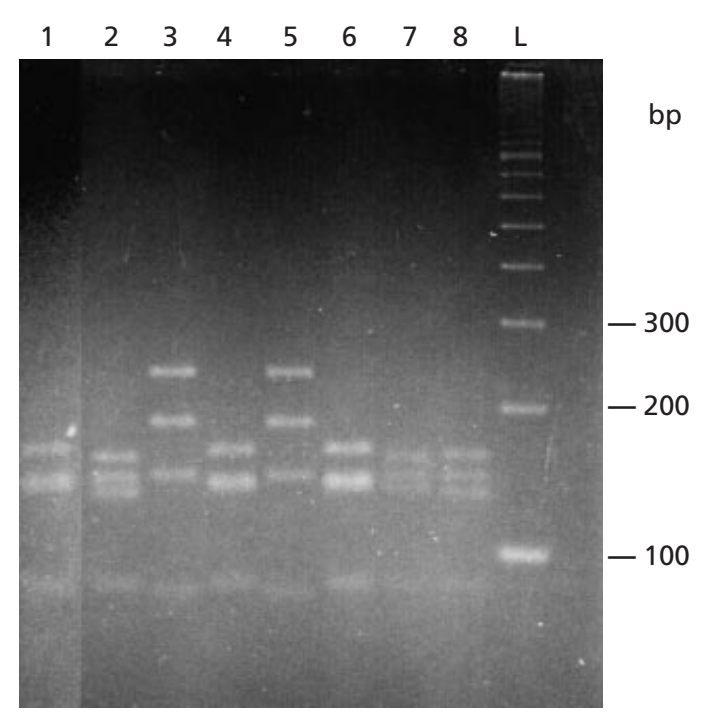

Fig. 2. RFLP of the ITS amplicons of one axenic and seven nonaxenic Prochlorococcus strains obtained with primers 600 and 340 and digested with Alul. Lanes: 1, PCC $9511^{\top}$ (axenic); 2, TAK 9803-2; 3, NATL1-MIT; 4, NATL2; 5, SS120; 6, OLI 36 FJA; 7, SB; $8, \mathrm{GP2} ; \mathrm{L}, 100 \mathrm{bp}$ molecular mass ladder. Note that for convenience of presentation, the digest of the ITS amplicon of the axenic strain PCC $9511^{\top}$ (lane 1), examined on the same gel but not located next to the other Prochlorococcus strains, was added using Adobe Photoshop.

gave no amplicons with cells of the cyanobacterium Microcystis aeruginosa PCC 7941 and lysates of the bacterial strains isolated from the impure Prochlorococcus cultures (data not shown).

The sizes of the bands observed after amplification of the impure Prochlorococcus strains with primer set 600 and 340 (Table 2) were in accordance with those determined for the major PCR products obtained with primer pair 322 and 340 (Table 2). Again it was possible to distinguish strains SS120 and NATL1-MIT from the other six Prochlorococcus isolates by their larger ITS size (about 640 versus $540 \mathrm{bp}$ ). The latter two strains correspond to members of the LL clade whereas, like the axenic strain PCC $9511^{\mathrm{T}}$, four of the remaining five (NATL2, TAK 9803-2, GP2 and SB; Table 2) are representatives of the HL clade (Urbach et al., 1998; West \& Scanlan, 1999; West et al., 2001; see also Table 2). The phylogenetic position of strain OLI 36 FJA is unknown, but based on its ITS size (about $550 \mathrm{bp}$ ) would also be assignable to the HL clade. The size of the ITS of the impure strain of 'Synechococcus' TAK RED (830 bp; see Fig. $1 \mathrm{~b}$ and Table 2) proved again similar to that of the axenic 'Synechococcus' WH7803 (820 bp; see Fig. 1a, b and Table 2).

\section{Restriction fragment length polymorphism (RFLP) of the ITS amplicons}

The ITS amplicons of the seven non-axenic Prochlorococcus isolates and of the axenic strain PCC 9511 obtained with primer set 600 and 340 were digested with seven different restriction enzymes. Although no cutting sites could be identified for any of the ITS amplicons with the enzymes EcoRI, EcoRV and HindIII (not shown), RFLP was observed with the remaining four enzymes tested (Table 2). A representative gel of amplicons restricted with $A l u \mathrm{I}$ is shown in Fig. 2. Depending on the restriction enzyme employed, the RFLP patterns were composed of two to four bands between 70 and 500 bp (Table 2) and it was possible to distinguish three RFLP subclusters (I.1, I.2A and I.2B) among the strains that yielded a small ITS amplicon (about $600 \mathrm{bp}$; Table 2). Subcluster I.1 regroups the HLI strains PCC $9511^{\mathrm{T}}$ and NATL2 (West \& Scanlan, 1999; Rippka et al., 2000) and includes OLI 36 FJA, whose phylogenetic position was previously unknown. Apart from fragments of short length (less than $70 \mathrm{bp}$ ) that were not detected (and thus the sum of the fragments may not add up perfectly to the size of the amplicons), the bands visualized by gel electrophoresis for the ITS amplicons of members of RFLP cluster I.1 are in good agreement with those expected on the basis of the restriction sites identified by DNA Strider 1.2 (Christian Marck, CEA, France) for the ITS sequence of Prochlorococcus MED4 (from the genome sequencing project) and that of Prochlorococcus PCC $9511^{\mathrm{T}}$ (see below). The latter analysis also confirmed the existence of restriction fragments of similar size (139 and $141 \mathrm{bp}$ for AluI and 207 and $209 \mathrm{bp}$ for HinfI) that are only revealed as a single band ('doublets', Table 2) of slightly stronger ethidium bromide fluorescence on the gels (see also Fig. 2, after restriction of the amplicons with AluI).

Strains of RFLP subclusters I.2A and I.2B (TAK9803-2, GP2 and SB) correspond to the HLII clade (West \& Scanlan, 1999; West et al., 2001), but strain TAK9803-2 (subcluster I.2A) differs by having the same HaeIII RFLP profile as strains of subcluster I.1, whereas strains GP2 and SB (subcluster I.2B) share a distinct banding pattern with this enzyme (Table 2). In contrast, strains Prochlorococcus SS120 and NATL1-MIT, that resulted in a larger ITS amplicon (about $700 \mathrm{bp}$; Table 2) and correlate with the LL clade (Urbach et al., 1998; West \& Scanlan, 1999; Rippka et al., 2000), could not be further subdivided by ITS RFLP with the number of enzymes examined (Table 2).

\section{Sequences and alignments of the ITS}

The sequences of the ITS regions were determined for Prochlorococcus PCC $9511^{\mathrm{T}}$ and two of the 'Synechococcus' strains (PCC 6307 and PCC 7001). They were compared to those of Prochlorococcus MED4 and MIT9313, using as a reference the cyanobacterial ITS alignment proposed by Iteman et al. (2000). In agreement with previous conclusions concerning the possible identity of strains Prochlorococcus PCC $9511^{\mathrm{T}}$ and MED4 (Rippka et al., 2000), sequence comparison demonstrated that the ITS of these two strains are identical (data not shown). Consequently, the ITS sequence of strain MED4 was omitted from the alignment shown in Fig. 3. For the reasons discussed below, the alignment 
$16 \mathrm{~S}$ rRNA gene ITS region

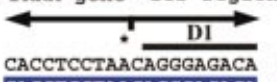

CACCTCCTAACAGGGAGACA A ctgatç" 40

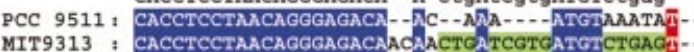

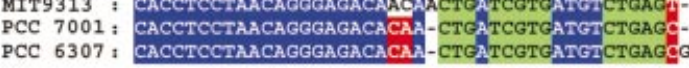

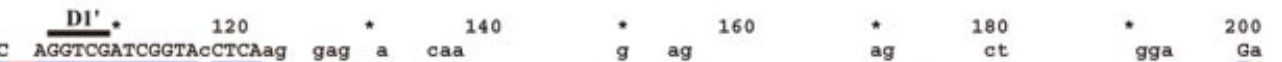

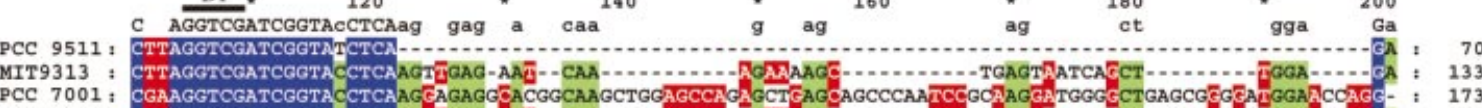

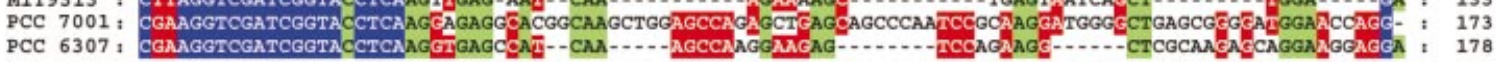

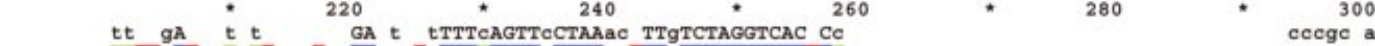

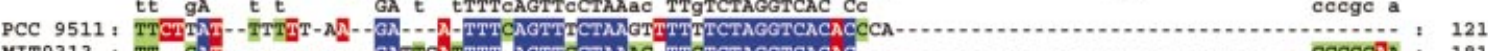

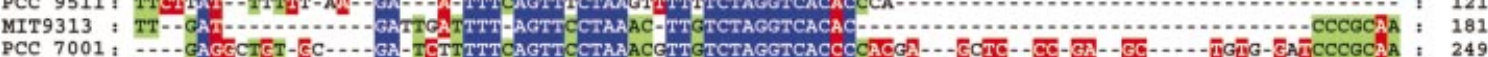

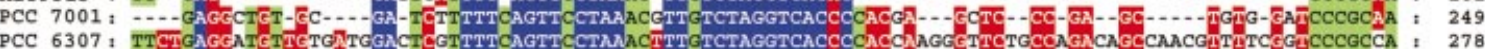

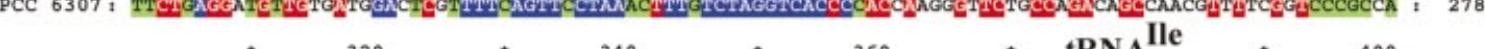

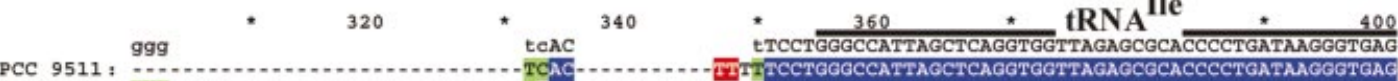

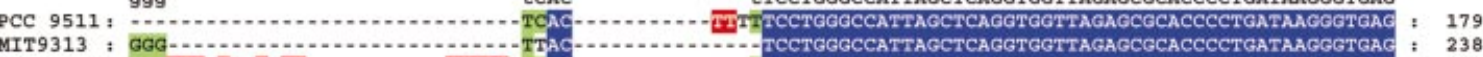

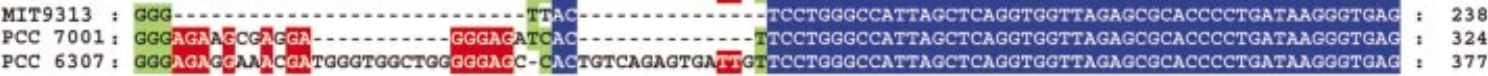

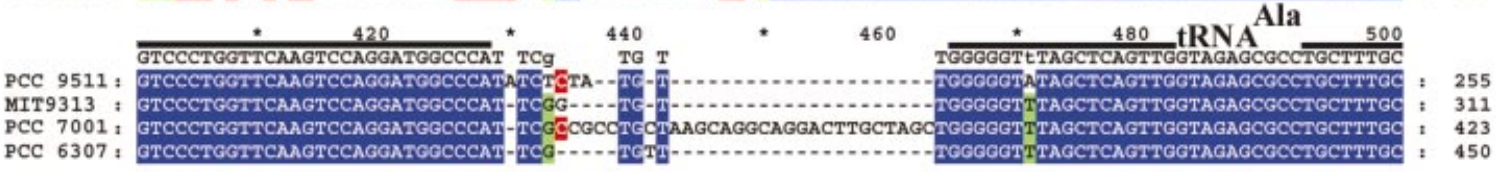

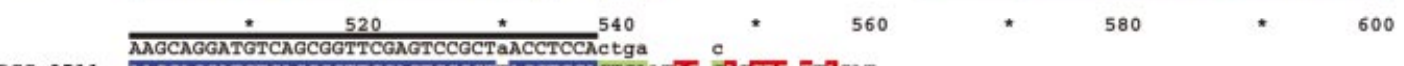
PCC 9511; AAGCAGGATGTCAGCGGTTCGAGTCCGCTIACCTCCACTGAATAC-CACCTC-[̈T

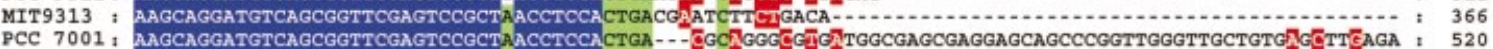

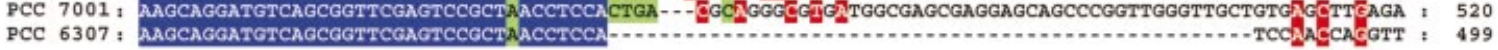

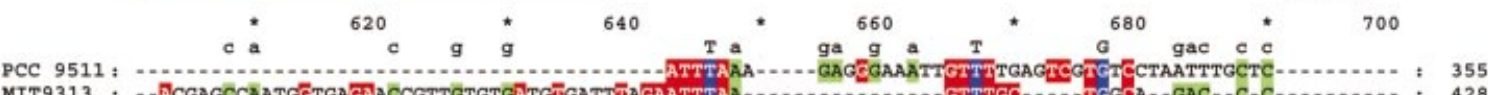

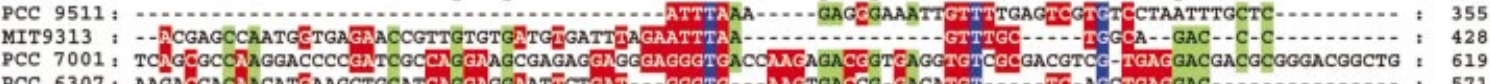

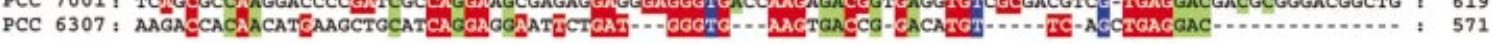

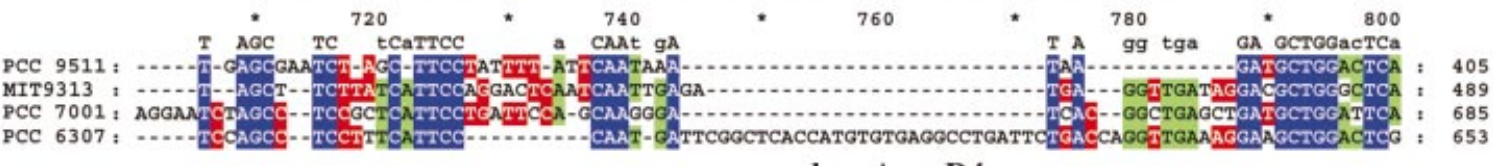

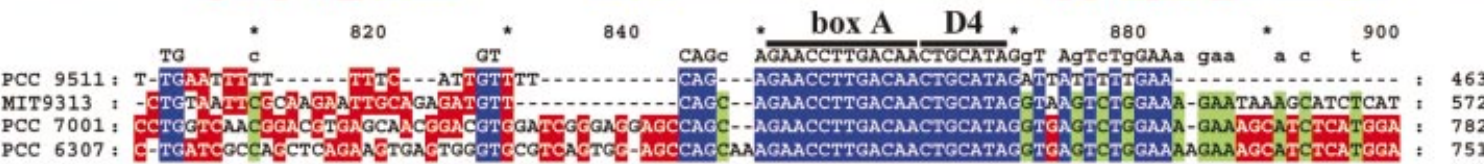

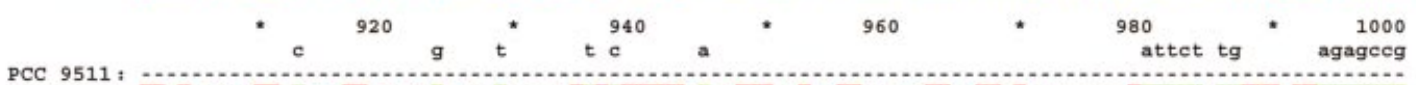

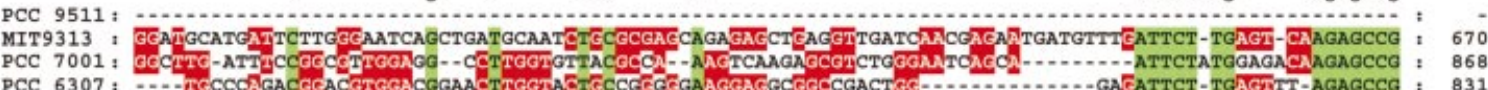

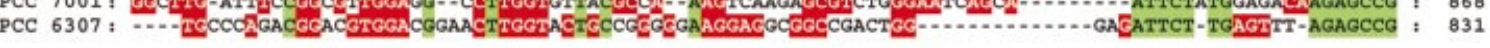

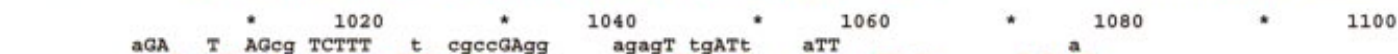

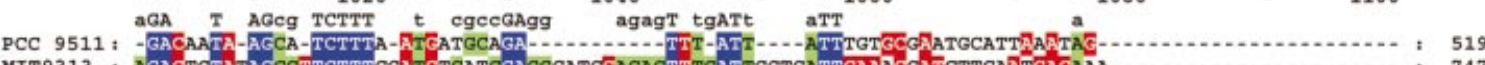

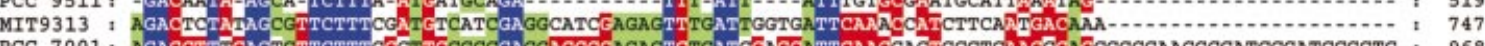

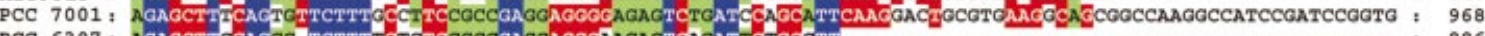

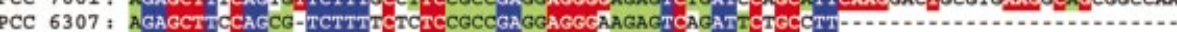

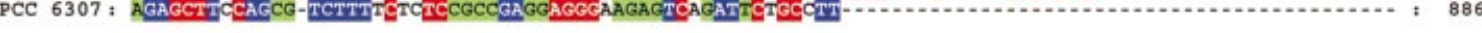

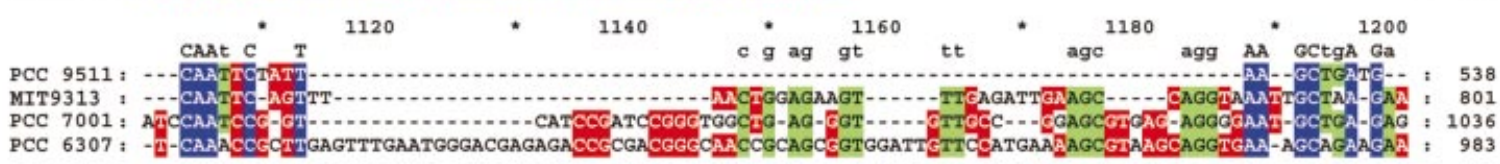

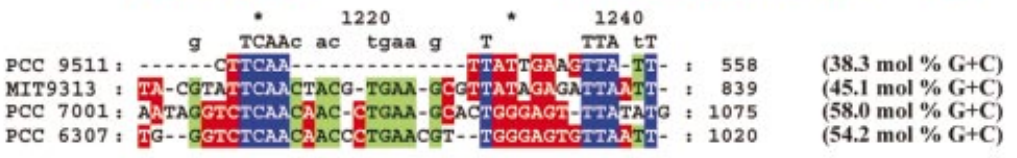

Fig. 3. Alignment of the nucleotide sequences of the end of the 165 rRNA gene and the ITS region of Prochlorococcus PCC 9511', Prochlorococcus MIT9313, 'Synechococcus' PCC 7001 and 'Synechococcus' PCC 6307. Percentage identity is 
also includes the last $10 \mathrm{nt}$ of the $16 \mathrm{~S}$ rRNA gene. This region, together with that covering the first $10 \mathrm{nt}$ of the ITS, is fully conserved in all sequences compared (Fig. 3), including MED4 (data not shown). In agreement with the approximate relative molecular mass determined for the ITS amplicons (see Fig. 1a, b and Table 2), the ITS sequences for Prochlorococcus PCC $9511^{\mathrm{T}}$ (and MED4), 'Synechococcus' PCC 6307 and PCC 7001 are 548, 1010 and 1065 bp in length, respectively. Strain Prochlorococcus MIT9313, a deeply branching member of the LL clade (Moore et al., 1998; West \& Scanlan, 1999; West et al., 2001), has an ITS of intermediate length $(829 \mathrm{bp})$, compared to the two HLI strains Prochlorococcus PCC $9511^{\mathrm{T}}$ and MED4 and strains 'Synechococcus' PCC 6307 and PCC 7001 (Fig. 3), but is similar in size to the ITS of 820 and 830 bp determined, respectively, for the oceanic 'Synechococcus' strains WH7803 (Fig. 1a, b; Table 2) and TAK RED (Fig. 1b; Table 2).

The mean DNA base composition of the ITSs also differ considerably, being lowest for Prochlorococcus PCC $9511^{\mathrm{T}}(38.3 \mathrm{~mol} \% \mathrm{G}+\mathrm{C}$ ), intermediate for Prochlorococcus MIT9313 (45.1 mol \% G + C, as determined from the genome sequencing project) and significantly higher in the two 'Synechococcus' strains PCC 6307 and PCC 7001 (54.2 and $58.0 \mathrm{~mol} \% \mathrm{G}+\mathrm{C}$, respectively).

In spite of the differences in size and base composition, as well as extensive sequence divergence in the more variable regions of the four ITS sequences aligned, common conserved domains, such as the two tRNA genes (encoding tRNA ${ }^{\text {Ile }}$ and tRNA ${ }^{\text {Ala }}$ ), could be identified (Fig. 3) and also include box A and motifs D1, D1' and D4 (Fig. 3), the former being important for transcriptional antitermination, the latter three for folding of the rRNA transcripts (Iteman et al., 2000).

\section{DISCUSSION}

The eight strains of Prochlorococcus examined (Table 2) could be subdivided into two ITS clusters by minor size differences (about 550 and $650 \mathrm{bp}$, corresponding to the HL and LL genotypes, respectively). However, the LL strain Prochlorococcus MIT9313, that in phylogenetic trees inferred from $16 \mathrm{~S}$ rDNA sequences is distinct from the above members of this genus (Moore et al., 1998; Urbach et al., 1998; Rippka et al., 2000; West et al., 2001), has a larger ITS (829 bp as revealed by the genome sequence) that is similar in size to that of the oceanic 'Synechococcus' strains WH7803 and TAK RED (about 820 and 830 bp, respectively, Table 2) and WH8102 (806 bp from the available genome sequence). Both the freshwater and coastal marine isolates 'Synechococcus' PCC 6307 and PCC 7001 that form a distinct clade in phylogenetic trees (Urbach et al., 1998; West \&
Scanlan, 1999; Rippka et al., 2000; West et al., 2001) could be distinguished from all the above strains by their very long ITS (1010 and $1065 \mathrm{bp}$, respectively), which even among bacteria is exceptional. Indeed, a survey of 855 bacterial ITS sequences presently available in GenBank revealed that only representatives of two genera (Bartonella and Bradyrhizobium) have an ITS of equivalent or slightly greater length.

In contrast to filamentous cyanobacteria that often have more than one rrn operon with ITS regions of at least two different sizes (Lu et al., 1997; West \& Adams, 1997; Neilan et al., 1997; Iteman et al., 1999, 2000; Barker et al., 1999), a single ITS amplicon was observed for all strains of Prochlorococcus and 'Synechococcus'. This may suggest that, like in the genomes of Prochlorococcus MED4 and MIT9313 and the oceanic 'Synechococcus' WH8102, a single rrn operon exists in all the strains examined here. However, it is also possible that, at least in some of these isolates, more than one copy of the rrn operon is present in their genome, but that the corresponding ITS regions are identical or very similar in size, as is the case for the unicellular cyanobacteria Synechococcus PCC 6301 and Synechocystis PCC 6803, both of which have two nearly identical ITSs (Williamson \& Doolittle, 1983; Tomioka \& Sugiura, 1984; Iteman et al., 2000). If multiple $r r n$ copies exist in the genomes of the strains of Prochlorococcus examined, both the sizes and recognition sequences of their ITS seem to be identical, since the sums of the restriction fragments are in fair agreement with the lengths of the ITS amplicons (Table 2) and not larger, as would be the case if there were sequence variations in the recognition sites.

The groupings obtained by RFLP of the ITS amplicons for the eight strains of Prochlorococcus examined, correlated well with the three different genotypes (HLI, HLII and LL) recognized on the basis of $16 \mathrm{~S}$ rRNA gene sequences (Urbach et al., 1998; West \& Scanlan, 1999; Rippka et al., 2000; West et al., 2001) and other molecular characterizations (Scanlan et al., 1996; Urbach et al., 1998; West \& Scanlan, 1999; West et al., 2001). This clearly demonstrates the overall value of this simple technique. However, it was not possible to discriminate between the two LL representatives SS120 and NATL1-MIT, although, based on 16S rDNA analyses, they are slightly more distant from one another than are the more interrelated HLI and HLII strains (Urbach et al., 1998; West \& Scanlan, 1999; West et al., 2001). Thus, for a higher level of discrimination between these two LL strains, analyses with a wider range of restriction enzymes or ITS sequence information will be required. The low degree of divergence in the $16 \mathrm{~S}$ rRNA genes between the most distantly related HL and LL representatives of Prochlorococcus $\quad(97 \cdot 3 \%$ similar-

represented by three colours: blue for $100 \%$, green for $75 \%$ and red for $50 \%$, gaps being treated as differences. Conserved motifs D1, D1', box A and D4 are indicated by reference to the ITS alignment and secondary structural models of the $r r n$ transcripts of Iteman et al. (2000). The G $+C$ values given at the end of the alignment are those of the ITS, with the last 10 bases of the 16S rDNA excluded. 


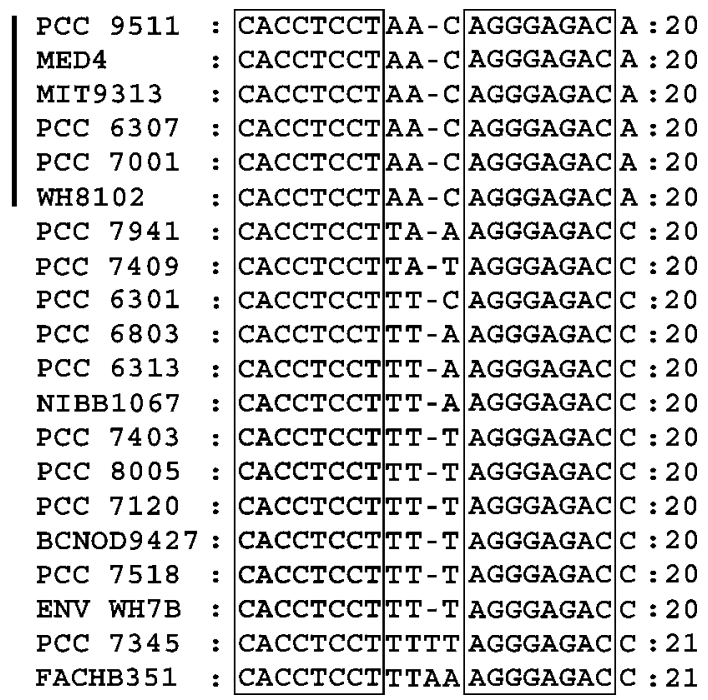

Fig. 4. Alignment of sequences overlapping the 165 rRNA gene and the ITS region of 20 cyanobacteria. The vertical bar on the left of the alignment indicates the cluster of strains sharing $100 \%$ identity; boxed motifs denote blocks of conserved domains within all the sequences presented. The sequences shown correspond from top to bottom to the following cyanobacterial strains or environmental clones: Prochlorococcus PCC 9511' , MED4 and MIT9313; 'Synechococcus' PCC 6307, PCC 7001 and WH8102; Microcystis PCC 7941; Pseudanabaena PCC 7409; Synechococcus PCC 6301; Synechocystis PCC 6803; Spirulina PCC 6313; Trichodesmium NIBB1067; Pseudanabaena PCC 7403; Arthrospira PCC 8005; Anabaena (Nostoc) PCC 7120; Nodularia BCNOD9427; 'Chlorogloeopsis' PCC 7518; environmental clone ENV WH7B; Arthrospira PCC 7345; and Spirulina subsalsa FACHB351. Accession numbers of the sequences used for this alignment are listed in Methods.

ity; West et al., 2001), suggests that the three RFLP groupings (I.1, I.2A and I.2B) obtained for the HL strains may correspond to distinctions at the subspecies level. In contrast, the larger ITS size and different RFLP profiles observed for the two LL strains, compared to all HL isolates, would be consistent with them being members of a different species. However, confirmation of these postulated taxonomic relationships needs to await DNA-DNA hybridization studies.

Analyses of the region covering the last $10 \mathrm{bp}$ in the $16 \mathrm{~S}$ rRNA gene and the first $10 \mathrm{bp}$ in the ITS for a total of 24 cyanobacteria, for which this sequence information is presently available (see Methods), revealed the specificity of the new primer 600. As shown in Fig. 4, only Prochlorococcus PCC 9511, MED4 and MIT9313, and strains PCC 6307, PCC 7001 and the oceanic 'Synechococcus' WH8102 show $100 \%$ sequence identity within the complementary target domain. For all other cyanobacteria, three or more mismatches could be identified (Fig. 4) and, as experimentally confirmed for the randomly chosen cyanobacterium Microcystis aeruginosa PCC 7941, are sufficient to prevent PCR amplification, if using an annealing temperature of $55^{\circ} \mathrm{C}$. Consequently, with this new group-specific primer the
ITS region can be selectively amplified from Prochlorococcus and all 'Synechococcus' strains of the OMF-'Synechococcus' clade, even if the cultures are contaminated by several different bacteria. The latter is particularly important for the genus Prochlorococcus, since only a single axenic strain (PCC $9511^{\mathrm{T}}$ ) of this genus is presently available (Rippka et al., 2000).

The $\mathrm{G}+\mathrm{C}$ content of the ITS (Fig. 3) correlated well with large differences in the mean DNA base composition determined for the total DNA of these organisms (Herdman et al., 1979b; Waterbury et al., 1986; Rippka et al., 2000), or deduced from the genome sequencing projects (for Prochlorococcus MED4 and MIT9313). The two HLI strains, Prochlorococcus PCC $9511^{\mathrm{T}}$ and MED4, have an identical ITS with the lowest $\mathrm{G}+\mathrm{C}$ content $(38.3 \mathrm{~mol} \% \mathrm{G}+\mathrm{C}$; see Fig. 3; for MED4, data not shown), reflecting the low mean DNA base composition (32 and $30 \cdot 9 \mathrm{~mol} \% \mathrm{G}+\mathrm{C}$, respectively) of their total genomic DNA. In contrast, the mean DNA base composition of the ITS for 'Synechococcus' PCC 6307 and PCC 7001 is much greater $(54.2$ and $58.0 \mathrm{~mol} \%$ $\mathrm{G}+\mathrm{C}$ ), which is largely consistent with their higher total DNA base composition $(69.7$ and $69.5 \mathrm{~mol} \%$ $\mathrm{G}+\mathrm{C}$, respectively). The deeply branching LL strain Prochlorococcus MIT9313 has an ITS of an intermediate $\mathrm{G}+\mathrm{C}$ content $(45 \cdot 1 \mathrm{~mol} \% \mathrm{G}+\mathrm{C})$ and the mean DNA base composition $(50.8 \mathrm{~mol} \% \mathrm{G}+\mathrm{C})$ of its genome is, like the length of its ITS ( $829 \mathrm{bp})$, closest to oceanic representatives of 'Synechococcus' (55-62 mol\% G+C; Waterbury et al., 1986). Thus, in contrast to the $16 \mathrm{~S}$ rRNA genes whose $\mathrm{G}+\mathrm{C}$ content spans a very narrow range $(53-55 \mathrm{~mol} \% \mathrm{G}+\mathrm{C}$ for Prochlorococcus and OMF-'Synechococcus' strains, compared to $51-59 \mathrm{~mol} \% \mathrm{G}+\mathrm{C}$ for the remaining 500 cyanobacterial $16 \mathrm{~S}$ rDNA sequences presently available in our database), even if the strains differ widely in total mean DNA base composition $(32-70 \mathrm{~mol} \% \mathrm{G}+\mathrm{C})$, it seems clear that the ITS region serves as a better indicator of divergence at the genomic level than the more conserved rDNA.

In spite of differences in size and mean DNA base composition, comparison of the new ITS sequences of Prochlorococcus PCC $9511^{\mathrm{T}}$ and the two 'Synechococcus' strains (PCC 6307 and PCC 7001) with those of Prochlorococcus MIT9313 (Fig. 3) and MED4 (data not shown), revealed valuable insights. Several conserved domains important either for transcriptional antitermination (box A) or folding (the complementary domains D1 and D1' close to the $5^{\prime}$ end of the ITS, together with domain D4 immediately adjacent to box A) of the rRNA transcripts were identified as in other cyanobacteria (Iteman et al., 2000) and two tRNA genes encoding tRNA ${ }^{\text {Ile }}$ and tRNA ${ }^{\text {Ala }}$ were found for all strains. This is in contrast to some other cyanobacterial ITSs that may lack one or both tRNA genes (Iteman et al., 2000). As in most other cyanobacterial ITS regions (Iteman et al., 2000), both tRNA genes lack the 3'terminal CCA extension found in many bacteria, although they contain the characteristic subterminal CCA sequence that appears to be typical of cyanobacteria 
(Iteman et al., 2000). The overall sequence similarity of the ITS sequences, including some of the more variable domains, was also higher among these five strains than that observed with respect to the ITS of other cyanobacterial genera (compare Fig. 3 with Fig. 3 of Iteman et al., 2000). However, major differences in sequence are evident in certain regions. Prochlorococcus MIT9313 differs from strain PCC 9511 in possessing a long insert (positions 883-1001; Fig. 3) and 12 short inserts situated throughout the ITS. These inserts are also observed in 'Synechococcus' strains PCC 6307 and PCC 7001, although the latter organisms differ in the positions of additional inserts that further increase the length of their ITS regions beyond that of strain MIT9313: the most significant of these start at alignment positions 44, 64, $181,258,304,336,589,746$ and 1116 for PCC 6307, and at 138, 157, 258, 304, 443, 556, 649, 691, 1078 and 1132 for PCC 7001. Since strains PCC 6307 and PCC 7001 differ markedly in sequence in certain regions, similar ITS sizes do not necessarily indicate close genetic relationships. However, in the case of Prochlorococcus MIT9313 and the oceanic 'Synechococcus' strain WH7803, for which the phylogenetic relationship is known (West et al., 2001), the similarity in length of this domain may be of significance. Indeed, in 16S rRNA gene trees, strain MIT9313 together with Prochlorococcus MIT9303, occupies a position that forms the root of the LL Prochlorococcus clade and is closest to the oceanic cluster of the OMF-'Synechococcus' clade (West et al., 2001).

The availability of the three new ITS sequences, together with those of Prochlorococcus MED4 and MIT9313, should permit the design of new primers that, in combination with the group-specific primer set 600 and 340 , may be used to achieve identification of strains or field samples at different resolution (i.e. at a lower or higher taxonomic rank) by PCR. In addition, probes complementary to discriminatory regions of the ITS may also be designed and labelled to attempt single-cell hybridization and detection by light microscopy or flow cytometry, possibly resulting in a higher specificity of identification than is presently achieved with probes targeting the more conserved 16S rRNA molecule (West et al., 2001; Worden et al., 2000). However, the search for such specific primers or probes will profit from the determination of additional ITS sequences. Finally, as more complete $16 \mathrm{~S}$ and $23 \mathrm{~S}$ rRNA gene and ITS sequences become available, secondary structure analyses will provide valuable insights into evolutionary aspects of these domains in the ribosomal operon of cyanobacteria from oceanic, marine and freshwater environments.

\section{ACKNOWLEDGEMENTS}

The authors wish to thank Nyree J. West and David J. Scanlan for having made available a phylogenetic tree of Prochlorococcus and oceanic 'Synechococcus' strains prior to publication. Annick Wilmotte and Gerard Van der Auwera kindly provided unpublished $16 \mathrm{~S} \mathrm{rDNA}$ and ITS sequence data. The work was supported by the Institut Pasteur, the
Centre National de la Recherche Scientifique (CNRS, URA 2172) and in part by the EC programme MAST 3-CT97-0128 (PROMOLEC).

\section{REFERENCES}

Barker, G. L. A., Hayes, P. K., O'Mahony, S. L., Vacharapiyasophon, P. \& Walsby, A. E. (1999). A molecular and phenotypic analysis of Nodularia (cyanobacteria) from the Baltic Sea. J Phycol 35, 931-937.

Brosius, J., Dull, T. J., Sleeter, D. D. \& Noller, H. F. (1981). Gene organization and primary structure of a ribosomal RNA operon from Escherichia coli. J Mol Biol 148, 107-127.

Campbell, L. \& Vaulot, D. (1993). Photosynthetic picoplankton community structure in the subtropical North Pacific Ocean near Hawaii (station ALOHA). Deep Sea Res 40, 2043-2060.

Castenholz, R. W. \& Waterbury, J. B. (1989). Oxygenic photosynthetic bacteria. Group I. Cyanobacteria. Preface. In Bergey's Manual of Systematic Bacteriology, pp. 1710-1727. Edited by J. T. Staley, M. P. Bryant, N. Pfenning \& J. G. Holt. Baltimore: Williams \& Wilkins.

Chisholm, S. W., Olson, R. J., Zettler, E. R., Goericke, R., Waterbury, J. B. \& Welschmeyer, N. A. (1988). A novel free-living prochlorophyte abundant in the oceanic euphotic zone. Nature 334, 340-343.

Chisholm, S. W., Frankel, S. L., Goericke, R., Olson, R. J., Palenik, B., Waterbury, J. B., West-Johnsrud, L. \& Zettler, E. R. (1992). Prochlorococcus marinus nov. gen. nov. sp.: An oxyphototrophic marine prokaryote containing divinyl chlorophyll $a$ and $b$. Arch Microbiol 157, 297-300.

Ferris, M. J. \& Palenik, B. (1998). Niche adaptation in ocean cyanobacteria. Nature 396, 226-228.

Herdman, M., Janvier, M., Rippka, R. \& Stanier, R. Y. (1979a). Genome size of cyanobacteria. J Gen Microbiol 111, 73-85.

Herdman, M., Janvier, M., Waterbury, J. B., Rippka, R., Stanier, R. Y. \& Mandel, M. (1979b). Deoxyribonucleic acid base composition of cyanobacteria. J Gen Microbiol 111, 63-71.

Herdman, M., Castenholz, R. W., Iteman, I., Waterbury, J. B. \& Rippka, R. (2001). Subsection I. (Formerly Chroococcales Wettstein 1924, emend. Rippka, Deruelles, Waterbury, Herdman and Stanier 1979). In Bergey's Manual of Systematic Bacteriology, 2nd edn, vol. 1, The Archaea and the Deeply Branching and Phototrophic Bacteria, pp. 493-514. Edited by D. R. Boone, R. W. Castenholz \& G. M. Garrity. New York, Berlin, Heidelberg: Springer.

Hess, W. R., Partensky, F., van der Staay, G. W. M., GarciaFernandez, J. M., Börner, T. \& Vaulot, D. (1996). Coexistence of phycoerythrin and a chlorophyll $a / b$ antenna in a marine prokaryote. Pro Natl Acad Sci US A 93, 11126-11130.

Hess, W. R., Steglich, C., Lichtlé, C. \& Partensky, F. (1999). Phycoerythrins of the oxyphotobacterium Prochlorococcus marinus are associated to the thylakoid membranes and are encoded by a single large gene cluster. Plant Mol Biol 40, 507-521.

Honda, D., Yokota, A. \& Sugiyama, J. (1999). Detection of seven major evolutionary lineages in cyanobacteria based on the $16 \mathrm{~S}$ rRNA gene sequence analysis with new sequences of five marine Synechococcus strains. J Mol Evol 48, 723-739.

Iteman, I., Rippka, R., Tandeau de Marsac, N. \& Herdman, M. (1999). Use of molecular tools for the study of genetic relationships of heterocystous cyanobacteria. Bull Inst Océanogr (Monaco) special issue 19, 13-20.

Iteman, I., Rippka, R., Tandeau de Marsac, N. \& Herdman, M. (2000). Comparison of conserved structural and regulatory 
domains within divergent $16 \mathrm{~S}$ rRNA-23S rRNA spacer sequences of cyanobacteria. Microbiology 146, 1275-1286.

Kane, M., Maeda, H., Fukunaga, T. \& Nishi, K. (1997). Molecular phylogenetic relationship between strains of cyanobacterial picoplankton in Lake Biwa, Japan. J Mar Biotechnol 5, 41-45.

Komárek, J., Kopecky, J. \& Cepák, V. (1999). Generic characters of the simplest cyanoprokaryotes Cyanobium, Cyanobacterium and Synechococcus. Cryptogam Algol 20, 209-222.

Li, W. K. W. \& Wood, A. M. (1988). Vertical distribution of North Atlantic ultraphytoplankton: Analysis by flow cytometry and epifluorescence microscopy. Deep Sea Res 35, 1615-1638.

Lu, W., Evans, H. E., McColl, M. \& Saunders, V. A. (1997). Identification of cyanobacteria by polymorphisms of PCRamplified ribosomal DNA spacer region. FEMS Microbiol Lett 153, 141-149.

Moore, L. R., Goericke, R. \& Chisholm, S. W. (1995). Comparative physiology of Synechococcus and Prochlorococcus: Influence of light and temperature on growth, pigments, fluorescence and absorptive properties. Mar Ecol Prog Ser 116, 259-275.

Moore, L. R., Rocap, G. \& Chisholm, S. W. (1998). Physiology and molecular phylogeny of coexisting Prochlorococcus ecotypes. Nature 393, 464-467.

Morel, A., Ahn, Y.-H., Partensky, F., Vaulot, D. \& Claustre, H. (1993). Prochlorococcus and Synechococcus: A comparative study of their optical properties in relation to their size and pigmentation. J Mar Res 51, 617-649.

Neilan, B. A., Stuart, J. L., Goodman, A. E., Cox, P. T. \& Hawkins, P. R. (1997). Specific amplification and restriction polymorphisms of the cyanobacterial rRNA operon spacer region. Syst Appl Microbiol 20, 612-621.

Olson, R. J., Chisholm, S. W., Zettler, E. R., Altabet, M. A. \& Dusenberry, J. A. (1990). Spatial and temporal distributions of prochlorophyte picoplankton in the North Atlantic Ocean. Deep Sea Res 37, 1033-1051.

Otsuka, S., Suda, S., Li, R., Watanabe, M., Oyaizo, H., Matsomuto, S. \& Watanabe, M. M. (1999). Phylogenetic relationships between toxic and nontoxic strains of the genus Microcystis based on $16 \mathrm{~S}$ to $23 \mathrm{~S}$ internal transcribed spacer sequence. FEMS Microbiol Lett 172, 15-21.

Palenik, B. (1994). Cyanobacterial community structure as seen from RNA polymerase gene sequence analysis. Appl Environ Microbiol 60, 3212-3219.

Palenik, B. \& Haselkorn, R. (1992). Multiple evolutionary origins of prochlorophytes, the chlorophyll $b$-containing prokaryotes. Nature 355, 265-267.

Partensky, F., Hoepffner, N., Li, W. K. W., Ulloa, O. \& Vaulot, D. (1993). Photoacclimation of Prochlorococcus sp. (Prochlorophyta) strains isolated from the North Atlantic and the Mediterranean Sea. Plant Physiol 101, 285-296.

Partensky, F., Hess, W. R. \& Vaulot, D. (1999). Prochlorococcus, a key marine photosynthetic prokaryote. Microbiol Mol Biol Rev 63, 106-127.

Penno, S., Campbell, L. \& Hess, W. R. (2000). Presence of phycoerythrin in two strains of Prochlorococcus isolated from the sub-tropical North Pacific Ocean. J Phycol 36, 723-729.

Postius, C. \& Ernst, A. (1999). Mechanisms of dominance: coexistence of picocyanobacterial genotypes in a freshwater ecosystem. Arch Microbiol 172, 69-75.

Rippka, R. \& Herdman, M. (1992). Pasteur Culture Collection of Cyanobacterial Strains in Axenic Culture. Catalogue and Taxonomic Handbook. Vol. 1: Catalogue of Strains. Paris: Institut Pasteur.
Rippka, R., Deruelles, J., Waterbury, J. B., Herdman, M. \& Stanier, R. Y. (1979). Generic assignments, strain histories and properties of pure cultures of cyanobacteria. J Gen Microbiol 111, 1-61.

Rippka, R., Coursin, T., Hess, W. \& 7 other authors (2000). Prochlorococcus marinus Chisholm et al. 1992 subsp. pastoris subsp. nov. strain PCC 9511, the first axenic chlorophyll $a_{2} / b_{2^{-}}$ containing cyanobacterium (Oxyphotobacteria). Int J Syst Evol Microbiol 50, 1833-1847.

Robertson, B. R., Tezuka, N. \& Watanabe, M. M. (2001). Phylogenetic analyses of Synechococcus strains (cyanobacteria) using sequences of $16 \mathrm{~S}$ rDNA and part of the phycocyanin operon reveal multiple evolutionary lines and reflect phycobilin content. Int J Syst Evol Microbiol 51, 861-871.

Sambrook, J., Fritsch, E. F. \& Maniatis, T. (1989). Molecular Cloning: a Laboratory Manual, 2nd edn. Cold Spring Harbor, NY : Cold Spring Harbor Laboratory.

Scanlan, D. J., Hess, W. R., Partensky, F., Newman, J. \& Vaulot, D. (1996). High degree of genetic variation in Prochlorococcus (Prochlorophyta) revealed by RFLP analysis. Eur J Phycol 31, $1-9$.

Shimada, A., Nishijima, M. \& Maruyama, T. (1995). Seasonal appearance of Prochlorococcus in Suruga Bay, Japan, in 19921993. J Oceanogr 51, 289-300.

Shimada, A., Maruyama, T. \& Miyachi, S. (1996). Vertical distributions and photosynthetic action spectra of two oceanic picophytoplankters, Prochlorococcus marinus and Synechococcus sp. Mar Biotechnol 127, 15-23.

Tomioka, N. \& Sugiura, M. (1984). Nucleotide sequence of the 16S-23S spacer region in the rrnA operon from a blue-green alga, Anacystis nidulans. Mol Gen Genet 193, 427-430.

Turner, S. (1997). Molecular systematics of oxygenic photosynthetic bacteria. Plant Syst Evol Suppl 11, 13-52.

Urbach, E., Robertson, D. L. \& Chisholm, S. W. (1992). Multiple evolutionary origins of prochlorophytes within the cyanobacterial radiation. Nature 355, 267-270.

Urbach, E., Scanlan, D. J., Distel, D. L., Waterbury, J. B. \& Chisholm, S. W. (1998). Rapid diversification of marine picophytoplankton with dissimilar light-harvesting structures inferred from sequences of Prochlorococcus and Synechococcus (cyanobacteria). J Mol Evol 46, 188-201.

Waterbury, J. B. \& Rippka, R. (1989). Subsection I. Order Chroococcales Wettstein 1924, emend. Rippka et al., 1979. In Bergey's Manual of Systematic Bacteriology, pp. 1728-1746. Edited by J. T. Staley, M. P. Bryant, N. Pfenning \& J. G. Holt. Baltimore: Williams \& Wilkins.

Waterbury, J. B., Watson, S. W., Valois, F. W. \& Franks, D. G. (1986). Biological and ecological characterization of the marine unicellular cyanobacterium Synechococcus. Can Bull Fish Aquat Sci 214, 71-120.

West, N. J. \& Adams, D. G. (1997). Phenotypic and genotypic comparison of symbiotic and free-living cyanobacteria from a single field site. Appl Environ Microbiol 63, 4479-4484.

West, N. J. \& Scanlan, D. J. (1999). Niche-partitioning of Prochlorococcus populations in a stratified water column in the eastern North Atlantic ocean. Appl Environ Microbiol 65, 2585-2591.

West, N. J., Schönhuber, W. A., Fuller, N., Amann, R. I., Rippka, R., Post, A. \& Scanlan, D. J (2001). Closely related Prochlorococcus genotypes show remarkably different depth distributions in two oceanic regions as revealed by in situ hybridization using $16 \mathrm{~S}$ rRNA-targeted oligonucleotides. Microbiology 147, 1731-1744. Williamson, S. E. \& Doolittle, W. F. (1983). Gene for tRNA ${ }^{\text {Ile }}$ and 
tRNA ${ }^{\mathrm{Ala}}$ in the spacer between the $16 \mathrm{~S}$ and $23 \mathrm{~S}$ rRNA genes of a blue-green alga: strong homology to chloroplast tRNA genes and tRNA genes of E. coli rrnD cluster. Nucleic Acids Res 11, 225-235.

Wilmotte, A. (1994). Molecular evolution and taxonomy of the cyanobacteria. In The Molecular Biology of Cyanobacteria, pp. 1-25. Edited by D. A. Bryant. Dordrecht: Kluwer.

Wilmotte, A., Van der Auwera, G. \& De Wachter, R. (1993). Structure of the $16 \mathrm{~S}$ ribosomal RNA of the thermophilic cyanobacterium Chlorogloeopsis HTF ('Mastigocladus lamino- sus HTF') strain PCC7518, and phylogenetic analysis. FEBS Lett 317, 96-100.

Worden, A. Z., Chisholm, S. W. \& Binder, B. J. (2000). In situ hybridization of Prochlorococcus and Synechococcus (marine cyanobacteria) spp. with rRNA-targeted peptide nucleic acid probes. Appl Environ Microbiol 66, 284-289.

Received 28 June 2001; revised 21 September 2001; accepted 2 October 2001. 